\title{
Carta desde mi ventana Una fatalista reflexión pandémica
}

Samuel Andrés Arias-Valencia ${ }^{1}$

Forma de citar: Arias-Valencia SA. Carta desde mi ventana. Una fatalista reflexión pandémica. Salud UIS. 2020; 52(4): 485-489. doi: https://doi.org/10.18273/revsal.v52n4-2020016 @(c) (1)

Querido Javier:

Agradezco la invitación que me has hecho, sobre todo porque escribirte esta carta me permite sacar la cabeza del agujero donde la tenía escondida y atreverme a asomarme a través de este texto a susurrar, a compartir contigo y con los lectores de la revista, algunas de las reflexiones que he realizado desde mi encierro voluntario, desde la comodidad privilegiada de este lado de la ventana, sobre la pandemia de Covid-19.

Sé que el pedido explícito que me hiciste fue un ensayo que diera cuenta de mi lectura de la pandemia en Antioquia, territorio donde en apariencia ha tenido un manejo menos peor, aunque vos, junto con otros colegas, en tu artículo reciente indicas que, al menos en el desempeño del sistema de vigilancia epidemiológica en los primeros 50 días, ha sido el mejor ${ }^{1}$. Digo menos peor porque considero que hay unos asuntos estructurales del modelo civilizatorio, de nuestra sociedad colombiana, de las decisiones políticas globales, nacionales y territoriales, que hacen que Colombia, a pesar de su heterogeneidad, sea, en mi opinión, toda un desastre, y Antioquia no es la excepción.

Te contaré entonces en esta carta, por qué mi lectura tan negativa del problema. Lo haré a través de narrarte mi experiencia y las sensaciones que he tenido para que durante estos meses hubiese enterrado la cabeza en la arena; luego, sin recurrir a la repetición de datos -que todos conocemos o podemos tener acceso con facilidad- te contaré mi valoración del comportamiento epidemiológico de la pandemia en nuestro territorio, mi lectura de las condiciones que han posibilitado lo que estamos viviendo, mi apreciación de la respuesta que se ha dado, la urgencia de un enfoque sindémico y, por último, mi desesperanzado augurio (lejos de pretender ser un pronóstico).

\section{¿Covid 19 o gripezinha?}

Javier, debo admitir que durante mucho tiempo le he sacado el cuerpo a sentar por escrito mis reflexiones sobre lo que ha venido pasando con la pandemia de Covid-19. Y no solo a escribir, también a actuar activamente como profesional frente al reto que ha implicado esta situación. Las razones han sido varias, pero tal vez se puedan expresar principalmente en tres palabras: frustración, miedo y desesperanza.

Todo comenzó el mismo día que se reportó el primer caso en Colombia, el viernes 6 de marzo de 2020 estaba en medio de una reunión del Instituto Nacional de Cancerología en Bogotá con los líderes de las regiones de la Red Nacional de Investigación en Cáncer cuando nos llegó la noticia. Para asistir a esa reunión tuve que viajar de Medellín a Bogotá la noche anterior y regresé a casa el sábado. El domingo estuve almorzando y en cine con mi esposa y mis hijas en un centro comercial de Envigado.

Unos cuantos días después comencé a enfermar. Yo tengo una susceptibilidad aumentada a las infecciones respiratorias, suelo decir exagerando que a mí me dan dos gripas al año y cada una me dura seis meses. Como me había sucedido en ocasiones anteriores, comenzó con tos seca y nada más, sólo que esta vez, se le sumó la diarrea, la fiebre y un decaimiento progresivo, sin llegar a tener dificultad respiratoria. Luego fueron mis dos hijas y mi esposa.

1. Universidad de Antioquia. Medellín, Colombia.

Correspondencia: Samuel Arias-Valencia. Dirección Calle 62 No. 52-59, Medellín, Antioquia. Teléfono: +574-2196434. Correo electrónico: samuel.arias@udea.edu.co 
En ellas la sintomatología duró apenas unos días, pero en mí, barrigón, hipertenso y casi cincuentón, duró más de tres semanas. Todo el tiempo estuvimos encerrados en casa, bueno, desde entonces estamos practicamente encerrados en casa. Para mí, la sospecha de que fuera Covid-19 era muy alta. Por esos días hasta ahora se estaban organizando los protocolos de vigilancia epidemiológica en el país y en los territorios; todavía no eran claras las responsabilidades de las aseguradoras, de los entes territoriales y aunque en Antioquia, particularmente en los municipios del Valle de Aburrá, el ejercicio de la vigilancia epidemiológica ha sido tradicionalmente juicioso y ordenado, al menos más que en otros territorios del país, estaban comenzando a entender y a organizarse frente a un asunto novedoso y desconocido. Reporté a la EPS, reporté al municipio de Sabaneta, reporté al municipio de Medellín, reporté por CoronApp-Colombia... nunca hubo una respuesta satisfactoria: tenía que haber viajado en las dos últimas dos semanas a China, España, Italia, Estados Unidos o México; de no ser así, tenía que tener entonces franca dificultad respiratoria que me obligara a consultar para poder acceder a la prueba. Fue frustrante. Desde entonces entendí el carácter prescriptivo que tendría el manejo de la pandemia: la realidad tenía que ajustarse a los protocolos, no los protocolos ajustarse a la realidad. La única posibilidad de transmisión era importada porque en Colombia no existía la transmisión comunitaria. No importaba la decisión tardía de cierre de los aeropuertos, la nula o poca rigurosidad con la que se hacía la vigilancia de los vuelos provenientes del extranjero o en las fronteras terrestres. Yo no podía tener Covid-19 porque el protocolo decía que aún no había transmisión comunitaria. Así las cosas, era imposible entonces que lo que tuve, la peor gripezinha que he padecido en mi vida, hubiese sido por SARS-CoV-2. Nunca lo pude confirmar ni descartar.

Entonces, se sumó el agotamiento de la enfermedad, la frustración frente al errático manejo que se dio a mi caso, el miedo a que esa cosa que tenía empeorará y la infoxicación a la que me sometí con cuanta publicación científica se me atravesaba, más las dramáticas noticias provenientes de España, Nueva York, y Guayaquil, etc. La interacción de esos ingredientes en ese coctel me puso en jaque, me invadió una sensación de desesperanza que no ha desaparecido hasta hoy. Decidí concentrarme en dos cosas: en el cuidado de mi familia y en los compromisos académicos de mi trabajo en la Universidad.

Mientras tanto, muchos de mis colegas salubristas y epidemiólogos se volcaron en un activismo sin precedentes alineados en la lucha anti-Covid. Algunos lo hicieron obedeciendo a Pepe grillo, a un llamado ético-político proveniente de sí mismos; otros, atraídos por el oportunismo de al fin ser protagonistas: ante tanto tiempo de ninguneo de nuestra labor en este sistema que desprecia la salud pública y la epidemiología, ¡al fin una oportunidad de brillar! Otros, un poco de las dos: buenos profesionales que los favorecen las luces de los reflectores. Como era de esperarse, ese entusiasmo inicial se ha ido apagando y depurando. Los que quedan, los que han persistido, han procurado hacer una labor juiciosa, en su mayoría silenciosa y poco reconocida.

Yo me marginé, me encerré, figurada y literalmente, no sin algo de culpa, mi Pepe Grillo a veces me susurra que tal vez hubiese podido ayudar, pero no lo creo; a pesar de todo el trabajo juicioso, riguroso y comprometido de nuestros profesionales de la salud, tanto clínicos como salubristas, a pesar de todo el esfuerzo, esto es un desastre. La excusa que me doy para atenuar mi culpa, es que varios de quienes están liderando y lidiando día a día con esta compleja situación en diferentes regiones del país han sido mis alumnos y alumnas, me consuelo con pensar que algo de mí ronda por ahí en la labor que hacen; aunque lamento profundamente que muchos de ellos, al igual que los clínicos, son muy mal remunerados, tienen contratos precarios y no cuentan con equipos suficientes y de calidad para realizar su labor.

\section{Covid-19: ¿Síntoma o enfermedad?}

¿Pero por qué tanto fatalismo? ¿Será solo una expresión más de mis síntomas depresivos? Es posible, sin embargo considero que el problema radica en que la Covid-19 no es la enfermedad, es apenas un síntoma bastante intenso, incluso patognomónico, de la grave enfermedad que padecemos como sociedad.

No me voy a detener en el acumulado de casos de enfermos y muertos que tenemos y que nos ubican entre los primeros (peores) lugares en el mundo, no sólo en números absolutos, sino en indicadores con denominador poblacional, tampoco me detendré en el escaso número de pruebas que hacemos en Colombia, en la pírrica relación entre número de pruebas y casos diagnósticados, ni en la cantidad de pruebas por millón de habitantes que se vincula con un importante subregistro de nuestros datos, ni de la mentirosa "cuarentena más larga del mundo" con el mayor 
número de excepciones del mundo, ni del caótico funcionamiento del programa de pruebas, rastreo y aislamiento selectivo, que aún en los territorios en que mejor se ha hecho, como Antioquia, Bogotá, Nariño, Valle y Tolima ${ }^{1}$, la tarea ha sido insuficiente.

Quiero plantear cómo la situación que estamos viviendo, particularmente en Colombia, es una manifestación más, una consecuencia, de la profunda y creciente brecha de inequidad social y sanitaria que vivimos en el mundo ${ }^{2-5}$.

El relato dominante de esta pandemia ha sido narrado a partir de un enfoque bioclínico. El virus SARS-CoV-2, más allá de la discusión bizantina de su origen, una porción de murciélago sumergida en una sopa de Wuhan o el maquiavélico plan orquestado en China para adueñarse del mundo a partir de la liberación del virus, es más que un problema clínico que produce una gripezinha o falla respiratoria o una tormenta de citocinas o una falla multiorgánica en los individuos enfermos. La pregunta que ronda este fenómeno es cuáles son las condiciones que posibilitaron que esto se esté presentando. ¿Es solo un evento fortuito dado por el azar en la interacción biológica entre especies? No, yo considero que hay determinantes antrópicos no sólo para el caso índice sino, sobre todo, para la expansión de la infección. Sin duda, el virus comenzó su expansión viajando en clase ejecutiva, pero sobre todo en clase turista, viajes en un mundo globalizado vinculado a dinámicas económicas extractivistas que alteran y destruyen los ecosistemas, que nos ponen en cuenta regresiva para nuestra viabilidad como especie en este planeta y que fomentan cambios e interacciones inesperadas como el encuentro entre el SARS-CoV-2 y nosotros, los homo ridiculus.

Ahora el relato biomédico prosigue con la identificación de factores de riesgo para los casos graves y la muerte por Covid-19, factores de riesgo como la edad, un mayor riesgo para adultos mayores, la presencia de enfermedades crónicas: hipertensión, antecedentes de enfermedades respiratorias, obesidad, tabaquismo, etc. Sin embargo, poco a poco se ha develado que la enfermedad no se expande, no se distribuye al azar, sino que por el contrario, se comienza a consolidar evidencia importante que indica cómo el riesgo es mayor en territorios con predominio de poblaciones pobres, en personas migrantes, en minorías étnicas, en territorios con un deficiente acceso a servicios de salud oportunos y de calidad. Para la muestra solo basta ver el efecto de la pandemia en Leticia y el departamento de Amazonas. Por tanto, el riesgo no sólo se vincula con exposiciones específicas de individuos aislados (el viejo, el hipertenso, el fumador, etc.) sino con configuraciones sociales, culturales, económicas y ambientales que se dan en los territorios. Adicionalmente, el comportamiento de la pandemia nos ha enseñado lo sensible que es a la toma de decisiones políticas orientadas a su control. Es por eso que la pandemia desnuda, expone de manera cruel las profundas desigualdades injustas en nuestro país y en el mundo. En esta situación, cobran mayor sentido estas palabras de Amartya Sen:

"Lo que es particularmente grave como injusticia es que algunos pueden no tener la oportunidad de alcanzar una buena salud debido a acuerdos sociales, y no a una decisión personal de no preocuparse por su salud"6.

\section{La urgencia de un enfoque sindémico que nunca llegará}

Pero la enfermedad no sólo la padece el sujeto que tiene el virus en su cuerpo, la sufre su familia, su entorno cercano, su comunidad, su ciudad, su país. Es decir, la Covid-19 no es una enfermedad que afecta un organismo, es una enfermedad social; bueno, todas lo son, pero el carácter epidémico, pandémico, de ésta, su contagiosidad y alta letalidad, ponen más en evidencia esa ineludible dimensión social de toda enfermedad. Por tanto, las afectaciones no solo se dan en los individuos, ni siquiera en las poblaciones como sumatorias de individuos, como denominadores demográficos y epidemiológicos, se dan en el cuerpo, en las prácticas, en las relaciones sociales, económicas y sociales. Afectaciones que no aparecieron el seis de marzo de 2020 sino que corresponden a procesos sociohistoricos de configuración de desigualdades injustas y sistemáticas.

Por esa razón las acciones no pueden ser planteadas solo para el rebaño, con la connotación epidemiológica de la ilusoria inmunidad de grupo, pero a la vez la significación de docilidad y obediencia frente al pastor, al policía, al Gran Hermano, al vigilante del panóptico, sino a transformaciones culturales, por una parte, que fomenten el cuidado como estrategia nuclear de prevención, y adicionalmente, a cambios estructurales que corrijan las brechas sociales inequitativas de nuestra sociedad que hacen parte integral de la enfermedad. 
Es por esto que considero importante y urgente la necesidad de una lectura sindémica de la pandemia; la necesidad de comprender el efecto sinérgico del fenómeno biológico y epidemiológico de la infección viral con las condiciones sociales, económicas, culturales, políticas y ecológicas; un enfoque donde lo uno es inseparable de lo otro y que tiene el propósito ético-político de corregir las injusticias sociales como parte integral de la solución a los problemas sanitarios $^{2,7,8}$. Por eso el hambre creciente en muchos hogares, el aumento de las enfermedades transmitidas por vectores, de la violencia de pareja y familiar, las masacres y los asesinatos de líderes sociales son parte de la pandemia. No es sólo la infección por SARS-CoV-2.

Desde esta perspectiva la cacería del número reproductivo básico dejaría de ser la única meta, al fin y al cabo, ya "aplanamos la curva", ahora persistimos desde hace semanas en una dolorosa y prolongada meseta de un par de centenares de muertes diarias... esa es nuestra "nueva normalidad".

Como le preguntaría Julio Sánchez Cristo en la radio a don Alberto Casas Santamaría:

“Alberto, ¿posibilidad de que se asuma un enfoque sindémico para el control de la pandemia en Colombia?”.

“Ninguna, Julito!”

Bueno, no sé si ninguna, pero al menos la veo muy remota. Como lo vengo describiendo, la narrativa dominante y las acciones emprendidas están centradas en la responsabilidad individual y en medidas biomédicas. Hacemos pseudo-cuarentenas, nos lavamos las manos, mantenemos la distancia social y usamos tapabocas para evitar el ingreso del virus al organismo; anhelamos, casi mendigamos una vacuna en medio de la desaforada competencia del complejo médico-industrial por su producción y las ganancias que derive y aumentamos la capacidad instalada de unidades de cuidados intensivos (aunque no contemos con los suficientes intensivistas) para poder dejar pastar libre al rebaño... bueno, no tan libre, pero no importa, lo esencial es garantizar la "reactivación económica", economía que venía apagándose desde antes del inicio de la pandemia. Ah, y que se infecten los que se tengan que infectar, que se hospitalicen los que se tengan que hospitalizar, que se mueran los que se tengan que morir. Eso sí, si llega a suceder será responsabilidad exclusiva de cada oveja obediente o desobediente a las prescripciones del Gran Hermano. Por eso la negación de una renta básica universal sin la que no puede funcionar el aislamiento selectivo ni mucho menos el aislamiento masivo cuando nuevamente nos toque volver a hacerlo. Nuestro Estado ni siquiera es un regulador, es un mero espectador de la voluntad de la mano invisible.

Vos me preguntabas por mi opinión de Medellín. Qué quieres que te diga sobre una ciudad que, frente a la crisis que vive de calidad del aíre, toma decisiones políticas que priorizan hacer plata, producir, por encima de respirar. Asunto que no es distinto frente a la situación que vivimos actualmente, solo que no es exclusivo de Medellín, ni de Colombia. Ese es el modelo de civilización en el que estamos. En donde la pandemia ha llegado para cambiarlo todo para que todo siga igual. Así como en la viñeta de Mafalda donde un hombre viejo le grita a un tipo barbado y melenudo: “¡esto es el acabóse!”. Mafalda ve la escena y le dice con la tranquilidad que la caracteríza: "no exagere, sólo es el continuóse del empezóse de ustedes".

Podrás decirme: "pero qué fatalista eres, Samuel. ¿Entonces no ves salida?” Sí, Javier, así es, siento una profunda desesperanza. Es posible que en varios años se supere la crisis epidemiológica de la pandemia por Covid-19, tendremos en nuestra cuenta varios millones de muertes, pero la crisis civilizatoria persistirá y yo presiento que estamos condenados a extingirnos como especie en este planeta o al menos a seguir perpetuándonos en una espiral de injusticia que aumentará el sufrimiento de quienes logren pervivir. Por fortuna la vida es terca y seguramente las verdaderas especies sabias sobreviviran a la peor plaga que le ha tocado a este diminuto planeta azul.

Amigo, un abrazo de los que no nos podemos dar,

Samuel

P.D. Javier, te mentí. Sólo veo una ínfima luz de esperanza y depende de poner en el centro de nuestro ser y hacer una Ética y una Política del Cuidado, que a la vez es una práctica que se construye de abajo hacia arriba. Allí tenemos mucho que aprender de nuestros pueblos originarios, sobre todo de nuestras mujeres. Pero eso lo dejo para una futura carta, si es que después de esta larga perorata me vuelves a invitar. 


\section{Referencias}

1. Manrique-Hernández EF, Moreno-Montoya J, Hurtado-Ortíz A, Prieto-Alvarado F, Idrovo ÁJ. Desempeño del sistema de vigilancia colombiano durante la pandemia de COVID-19: evaluación rápida de los primeros 50 días. Biomédica. 2020; 40(Supl.2). doi: https://doi.org/10.7705/biomedica.5582

2. Bambra C, Riordan R, Ford J, Matthews F. The COVID-19 pandemic and health inequalities. J Epidemiol Community Health. 2020; 74: 964-968. doi: http://dx.doi.org/10.1136/jech-2020-214401

3. Sachs JD, Abdool Karim S, Aknin L, Allen J, Brosbøl K, Cuevas Barron G, et al. Lancet COVID-19 Commission Statement on the occasion of the 75th session of the UN General Assembly. Lancet. 2020; S0140-6736(20): 31927-31929. doi: https://doi.org/10.1016/S0140-6736 en línea antes de imprimir

4. Basile G. SARS-CoV-2 en América Latina y Caribe: Las tres encrucijadas para el pensamiento crítico en salud. Cien Saude Colet. 2020; 25(9): 3557-3562. doi: https://doi.org/10.1590/1413-81232020259.20952020

5. Comisión Económica para América Latina y el Caribe, Organización Panamericana de la Salud. Salud y economía: una convergencia necesaria para enfrentar el COVID-19 y retomar la senda hacia el desarrollo sostenible en América Latina y el Caribe. Washington D.C.: Naciones Unidas y OPS; 2020. 27 p.

6. Sen A. Why health equity? Health Econ. 2002; 11(8): 659-666. doi: 10.1002 / hec.762

7. Singer M, Bulled N, Ostrach B, Mendenhall E. Syndemics and the biosocial conception of health. Lanceta. 2017; 389(10072): 941-950. doi: 10.1016 / S0140-6736 (17) 30003-X.

8. Singer M. Introduction to syndemics. A Critical Systems Approach to Public and Community Health. New Jersey: Jossey-Bass; 2009. 274 p. 